\title{
Animation as a computational framework for architectural design composition.
}

\author{
DOUNAS, T.
}

2020

This is an Accepted Manuscript of an article published by Taylor \& Francis in Architectural Science Review on

19/2/2020, available online: http://www.tandfonline.com/10.1080/00038628.2019.1709037 


\title{
Animation as a computational framework for architectural design composition
}

\author{
Theodoros Dounas
}

Scott Sutherland School of Architecture and Built Environment, Robert Gordon University, Aberdeen, UK

Robert Gordon University

t.dounas@rgu.ac.uk

\begin{abstract}
:
The paper develops computation, through dynamic grammars, as a third equivalent to syntactical and typological understanding of architectural design. Within theory of architectural design, syntactical and typological understanding of architecture are the two main scientific paradigms that explain how architecture is formed and conducted. As such the premise of the paper is to connect computational design as an equivalent understanding of architecture, one which has parity with the classical theoretical canon of the architectural design theories of the 20th century. To accomplish this, Dynamic grammars, i.e. shape grammars developed through animation are presented and analysed along with their mechanisms. Shape Grammars have been selected as a vehicle for this as they provide an excellent model of architectural com- position with computational design, using simple mechanisms. A case study of constructivist design is analysed using dynamic grammars, showcasing the elegance and efficiency of the system in describing variants of design, maintaining parity in a syntactical and a typological understanding of design. The paper concludes with the characteristics that a computational understanding of architectural design has.
\end{abstract}

\section{Introduction and Background}

The paper discusses the focused moment in architectural design creation, i.e. the moment when ideas are formulated and structured, as self-contained assemblies of structure, form and organization. The paper explores where architectural ideas come from, how they are formulated, and it attempts to connect three distinct understandings of architectural composition, the syntactical, the typological and the computational. The paper uses the generation of prototypical architectonic ideas to discuss this connection. To achieve this, all three understandings of architectural composition are presented as hypotheses of how composition comes to be and under the principles that govern it. While typological and syntactical understandings of architectural com- position are commonplace and form a classical cannon-most of it developed during the twentieth century- computational principles of architectural composition are rarely explored beyond computational research, i.e. they do not often relate with the typological and syntactical understandings. As such the paper attempts to relate the computational and digital development in architectural practice with already existing understandings and theory of architectural practice, rather than espouse computation as something radically different.

\section{Organisation of the paper}

The paper at first describes the typological and syntactical hypotheses for architectural design and makes a case for their parity, beyond their difference in surface. Then computation design is introduced via shape grammars, with emphasis given to a particular form, dynamic grammars, i.e. shape grammars implemented via animation. The paper then presents the methodology of using research on design, to research and unravel computational design tools. In the third part, a case study of dynamic grammars is presented and analysed. The paper then concludes discussing parity of computational design with the syntactical and typological understandings of architectural composition, through a brief discussion of their traits. Conclusions and further work for validation are presented in the final part of the paper. 


\section{Theories of Architectural Design}

Kotsiopoulos analyses in his book 'A critique of architectural theory' the main strands of architectural theory and how they relate to architectural practice, in an effort to overcome the diffi- culty architects have in phrasing a scientific framework for their practice (Kotsiopoulos 1994). He frames the main strands of the- ory in the twentieth century, according to how they answer the question of how meaning is created in architectural design. The syntactical and analytical strand, mainly represented by Hillier and Hanson (1989), expresses a model for the syntax of space, based on prototypical concepts of boundary, permeability, dif- ferentiation and contiguity (Figure 1).

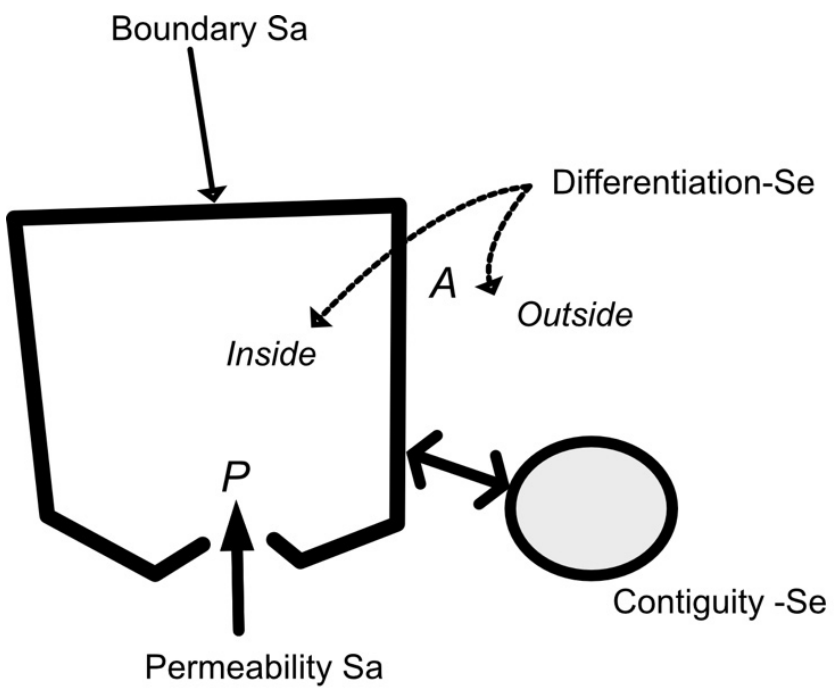
Hillier and Leaman's basic principles,
Expressed in animation armatures

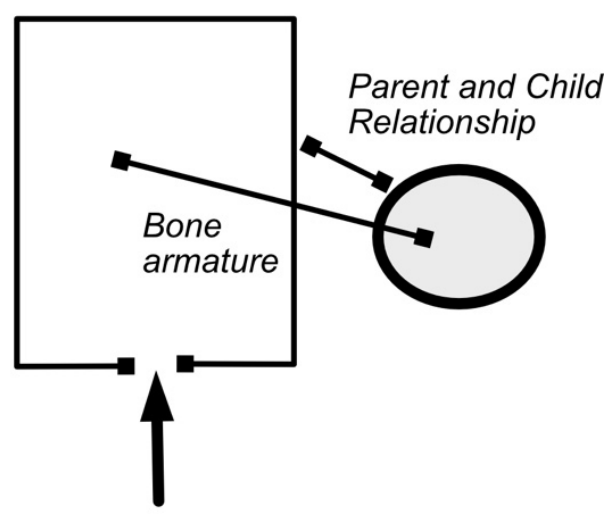

Figure 1: Hiller's and Leaman basic principles - juxtaposition with an expression of the basic principles in animation armatures.

With these concepts in hand, Hiller and Hanson proceed into building meaning into the structure of space, by using actions on the prototypical concepts: Transformation of one, repetition $\mathrm{D}$, transformation of repeating many $M$, definition of a higher class boundary $\mathrm{R}$. By using these actions, Hillier et al., claim that we construct structures of a higher class towards synthesizing the built environment, by using rules at a higher level than the actions, such as the continuity rule, as in everything is based on something that is already there, the vertex rule, where planes, not vertices, get connected, and other rules such the rule of simplicity, denseness, completeness. These rules are defined in a framework of conditions that avoid a deterministic character. These are all organized, according to Hillier and Hanson to a syntax of a higher order of the structure of space that can be expressed with the commutative square (Hillier and Leaman 1974) (Figure 2).

The commutative square is essentially, according to Kot- siopoulos, a structure that is borrowed by categoric algebra, a mechanism to understand the syntactic logic of Hiller and Hanson. It introduces the understanding that meaning in archi- tectural design emerges when one builds complexity from sim- ple components. The commutative square is an almost auto- matic mapping of the actions between human behaviour and design actions. This brings to the fore the core of Hiller and Hanson's argument about space, and consequently about archi- tecture: Space syntax has autonomy, and as such social aspects of space can be researched through the investigation of how such mappings are created and formed (Hiller 
and Leaman 1974). This introduces the possibility that there can be a com- plete, autonomous, minimal language of space. However, the embedding of meaning and social aspects drive the space syntax research paradigm towards studying and investigating how the built environment performs rather than how architects design. According to Kotsiopoulos, For Hillier, space and society are intrinsically linked, and 'architects can not avoid that relation- ship, even if they do it unconsciously' (Hillier 2015).

\section{D, Fmax, Pmax}

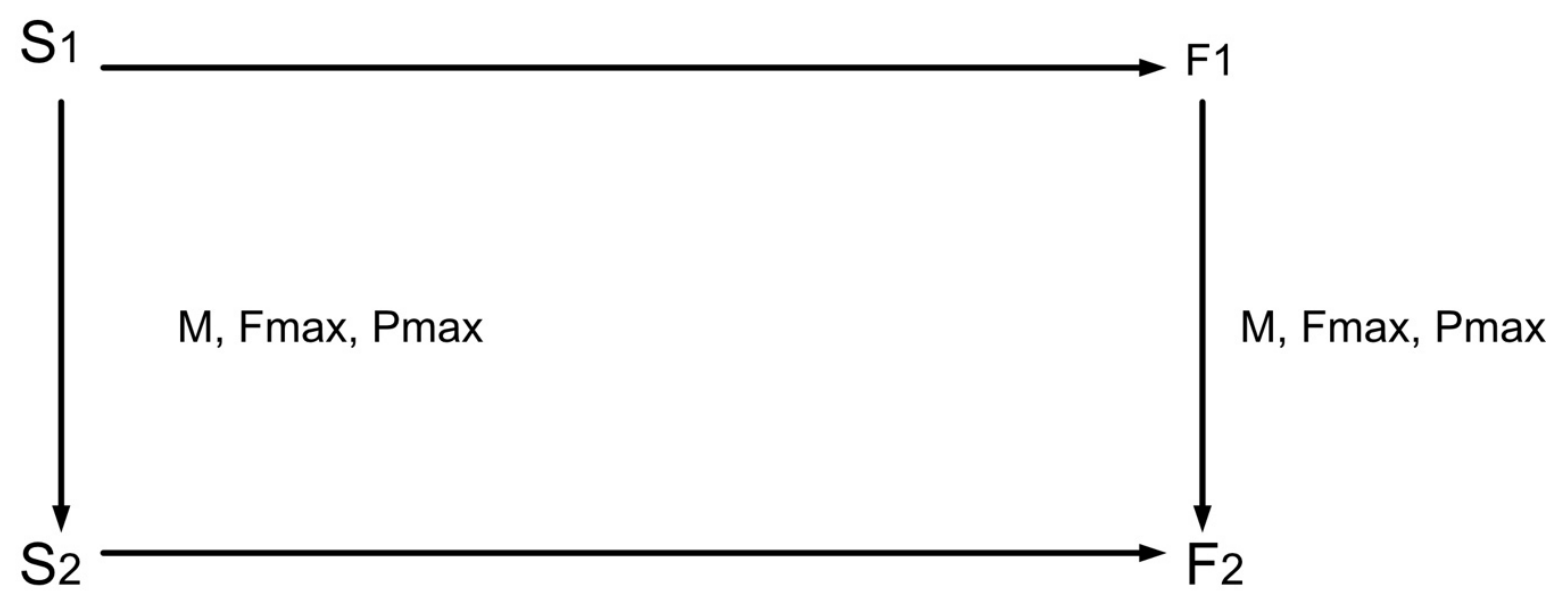
F - Contiguity
D, Fmax, Pmax

$P$-Permeability

$M, D$ - Operations, transformation rules

$\mathrm{S} 1, \mathrm{~S} 2, \mathrm{~F} 1, \mathrm{~F} 2$, objects of variant structure

Figure 2: Commutative square by Hillier

\section{The deep Structures of Architecture, by G.Broadbent.}

The theory of deep structures in architecture by Broadbent (1980), introduces four deep structures that architecture uses, which modulate the meaningful relationship of humans with their built environment, in the same manner, that language modulates the relationship of meaning with how humans express themselves. Broadbent's attempts to explain all of architectural design, by accepting four deep structures: those that set the building as a vessel of human activities, those that act as a modulator of climate, those that act as a cultural symbol, and as a consumer of resources. Buildings as vessels of human activities mean that buildings will have minimum sizes and scale enough to contain human activity, while the building as a climatic modifier means that the surfaces of the buildings will act as regulatory boundaries or filters between inside and outside. Within the culture, the building acts as a cultural symbol, even if the architect never intended it to, for example in functionalist architecture. The fourth structure means that the building acts as a value- added to the land, created by locating, resourcing, moving and organizing material resources in the form of the building. Kotsiopoulos proffers that these are potentially obvious elements of architecture, structured in such a manner as to be obvious. For example, out of the four deep structures is there one of them that lies deeper than the other three, one which is more fundamental than the others? Broadbend avoids the issue by focusing not on attempting to locate the deep structures in existing pieces of architecture but in constructing mechanisms of analysis on how architecture start from 
the four deep structures to assemble real buildings. Still Kotsiopoulos critiques the manner in which Broadbent's theory of deep structures remains a reading of architecture rather than a mechanism with which one can construct architecture. Within the theory of deep structures the mechanisms of creating architecture remain elusive, as one can not simple create architecture by using readings or analysis of it.

Moving away from the analytical methods of understanding and towards a typological one, the work of Christopher Alexan- der (1964) and the seminal work 'Pattern Language' (Alexander, Ishikawa, and Sliverstein 1977) attempts to classify patterns of space according to size, function, relationship with human activity, and map certain patterns as strategic for generating others. By attempting to create a hierarchy of patterns of space, we have a generative mechanism of space inherent within. Still, certain patterns in the Pattern language already contain fully formed spatial configurations, structures that are used to explain further developments of child-patterns. The criticism from the cultural understanding of architecture then remains towards patterns and structural understanding of architecture: signifiers of meaning do not need the generative power of patterns in space and architecture. On this however

Kotsiopoulos develops the positions on theory as an exploration on modernity and the modern movement, connecting proponents of syntactical approach to architectural design with proponents of the modern movement, and proponents of the pattern or typological approach to architectural design with a criticism on modernism. A. Colquhoun similarly (Colguhoun 1985) brings to the fore the spectrum of having to choose between an analytical approach and a typological approach in architecture. This spectrum is, in essence, the story of theories in the twentieth century in architectural design (Figure 3).

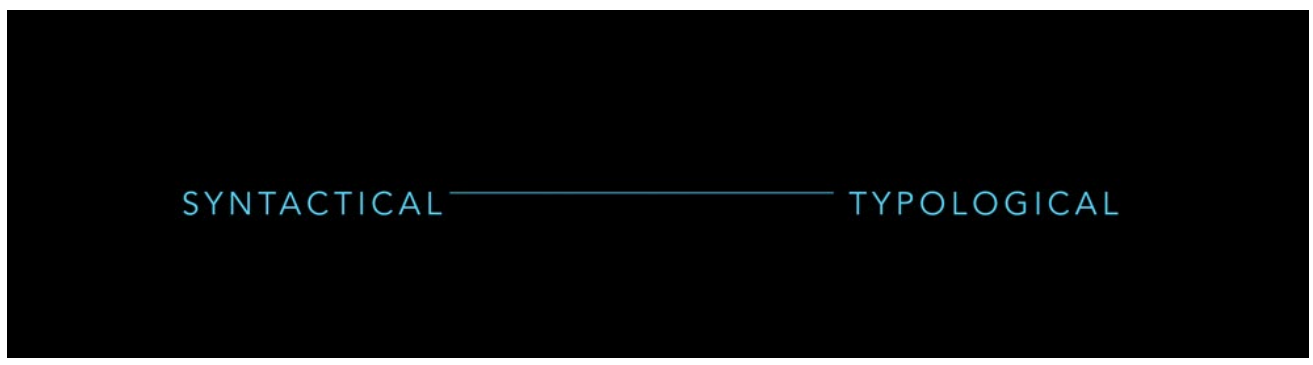

Figure 3: Analytical- Typological spectrum of understanding architecture.

\section{Methodology}

The paper uses methods of systemic analysis, qualitative analysis through the exploration of a design case study. Systemic and qualitative analyses of design case studies have been tested in terms of their relevance and efficiency in the design disciplines (Groat and Wang 2003; Rendell 2004; Frayling 1993). Groat et al. mention that qualitative analysis encloses a richness of data and a holistic approach to architectural research. Rendell (2004) by analysing the various methods of research in architecture, signifies three relationships of research methods with design itself, by using Frayling's model (1993): Research in Design, Research through Design, and Research for Design. The paper positions its methods in the first relationship, Research in Design, how- ever, the results and conclusion of the paper are positioned towards Research For Design. Having presented succinctly the analytical-typological spectrum of understanding architecture, the paper will now present shape grammars and their computational nature, a shape grammar implementation in animation, i.e. dynamic grammars, and the development of a design case study, where dynamic grammars are used to analyse and generate compositional variants of the Lenin Institute by Leonidov. 


\section{Shape Grammars.}

Shape grammars are formal productive systems that have developed through the initial foray of computing into (architectural) design. In their most basic form, they consist of a starting set of shapes, a starting set of rules and their termination shapes that end the application of the grammar. The classic definition of Shape Grammars is as follows (Stiny 2006):

A shape grammar is a 4-tuple (Vt, Vm, R, I) where

Vt is the initial set of shapes from where we are going to pick our starting shapes.

$\mathrm{Vt}^{*}$ is a set that contains any number of elements formed from elements belonging to $\mathrm{Vt}$, combined, rearranged and trans- formed in any number of ways.

$\mathrm{Vm}$ is a finite set of shapes so that the common set between $\mathrm{Vt}$ and $\mathrm{Vm}$ is null $\left(\mathrm{Vm}+\mathrm{Vt} \mathrm{t}^{*}\right)=0$ meaning that $\mathrm{Vm}$ does not contain any element belonging to $\mathrm{Vt}^{*}$.

$R$ is a set consisting of pairs of shapes, which when taken together form rules of the $U>V$ type. I is a set of shapes that consist of termination shapes, i.e. the shapes that when found by the user of the grammar terminate any further application of the rules. The use of the computer in the application of shape grammars encourages the generation of design alternatives, than in a 'traditional' design process would happen 'by hand' (Figure 4).

A
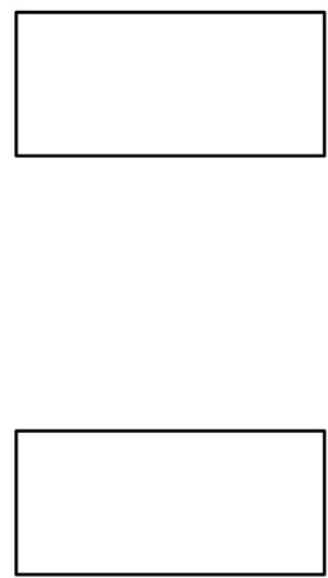

0
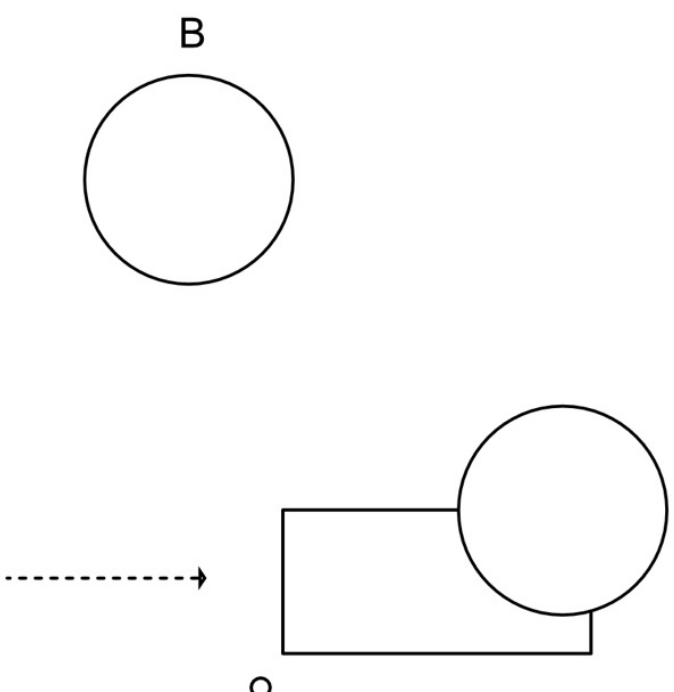

$V t=A, B$

$V t^{*}=A^{*}, B^{*} \quad l=d$

$R\left\{\begin{array}{l}R 1=C+C \\ R 2=C-C\end{array}\right\}$

rule application:

$\mathrm{R} 1=\mathrm{A}+\mathrm{B}$

Figure 4: Simple grammar expressed via shape, and via an algebraic notation. 
Shape Grammars have the capacity to act both at the level of the shape, with emergence and ambiguity (Knight 2003a, 2003b) and algebraically at the same time (Stiny 2006). As a simple productive mechanism, shape grammar are excellent formalisms of design activity (Duarte 2005; Economou 2001), and, while esoteric at points (Dounas 2013) due to their Turing completeness, they remain an excellent example of computation in design. This capacity, of being algebraic and work with emergence and ambiguity can be mapped against the spectrum of typological and analytical understanding of design. The typological understanding works at the level of algebra. During typological computational operations, a shape $\mathrm{S}$ is abstracted to a parameter $\mathrm{A}$ and that remains indivisible as a unit as operations continue. However, the analytical understanding of architectural composition might counter that with the shape $S$, there exist other shapes, that can be used to compute a new composition in the grammar. The shape grammatist though operates with this dual capacity at all times, hence why there is no preference between one or the other.

On a simple level this can represent at the same time the analytical and the typological understanding of architecture. As such, the paper makes the hypothesis that computation can stand as the third pole in the spectrum of understanding architecture.

Dynamic Grammars (Dounas 2008) employ the logic and structure of animation into architectural design ideas and map the shape grammar formalism into animation. This takes place through the transformation rules that are embedded into animation software, where the initial Vt, will be transformed through animation rules, $\mathrm{R}$, into the $\mathrm{Vt}^{*}$, terminating with I. Animation software contains tools that enable the user to structure the core of architectural design idea, while at the same time encapsulate the within the same grammar the generative process with which variants to the design are generated (Dounas and Kotsiopoulos 2006, 2007; Dounas 2008, 2009). Within (Dounas 2009) a parity between shape grammars and animation is discussed

at the computational level. Animation can encapsulate shape grammars and also create emergent shapes that are not predicted in the initial set Vt of the shape grammar, through the in- between frames between two keyframes, hence they are excel- lent mechanisms to capture computationally emergence and ambiguity, without losing the inherent algebraic condition of the rule transformation.

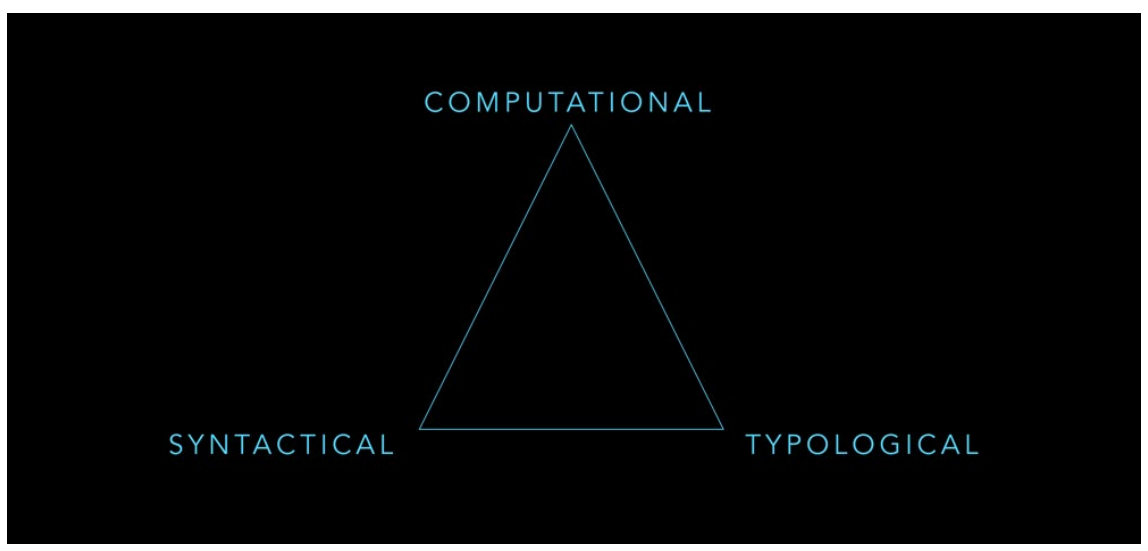

Figure 5: A computational framework for architectural design: a triple structure for understanding architecture. 
Taking into account this capacity of dynamic grammars, the paper analyses the design case study of the Lenin Institute by Ivan Leonidov, and implements dynamic grammars to generate variants of the design, in an effort to validate the position expressed in Figure 5: Computation is another, equivalent with the other two typological and analytical, understanding of architecture. However, in a supra manner, computation moves beyond understanding, into action and composition (Figure 6).

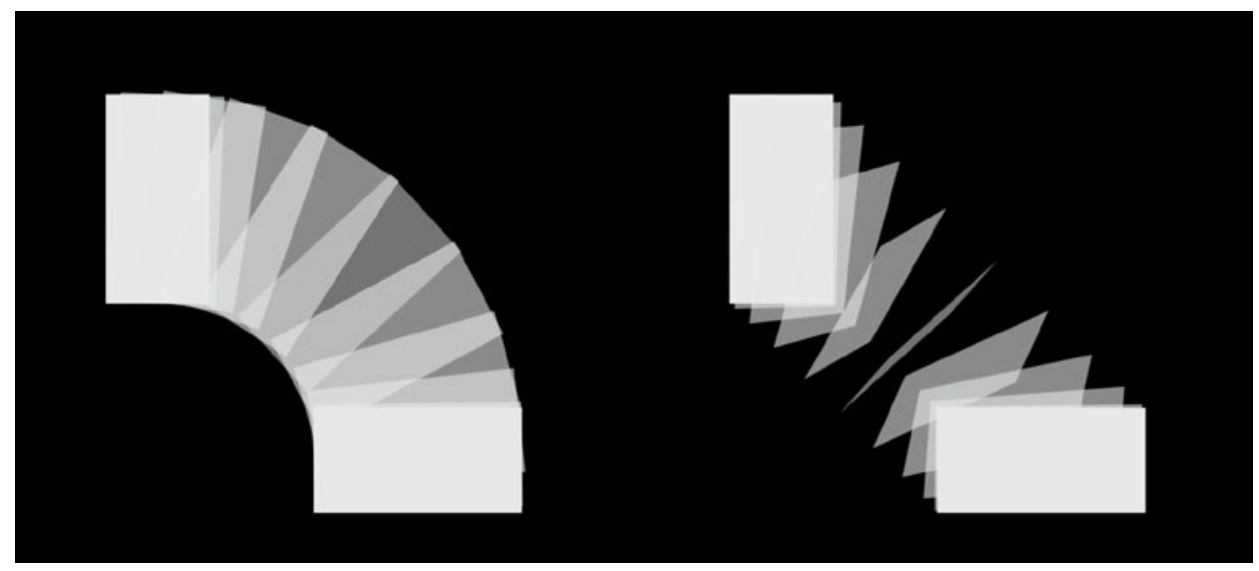

Figure 6: Animation mirror and animation rotation in applying the same transformation rule.

\section{Lenin Institute by Ivan Leonidov}

The case study analysed here is the Institute and Library 'Lenin' by Ivan Leonidov. This was the Leonidov diploma project to graduate from the Vhuketmas architecture school (Figure 7). 


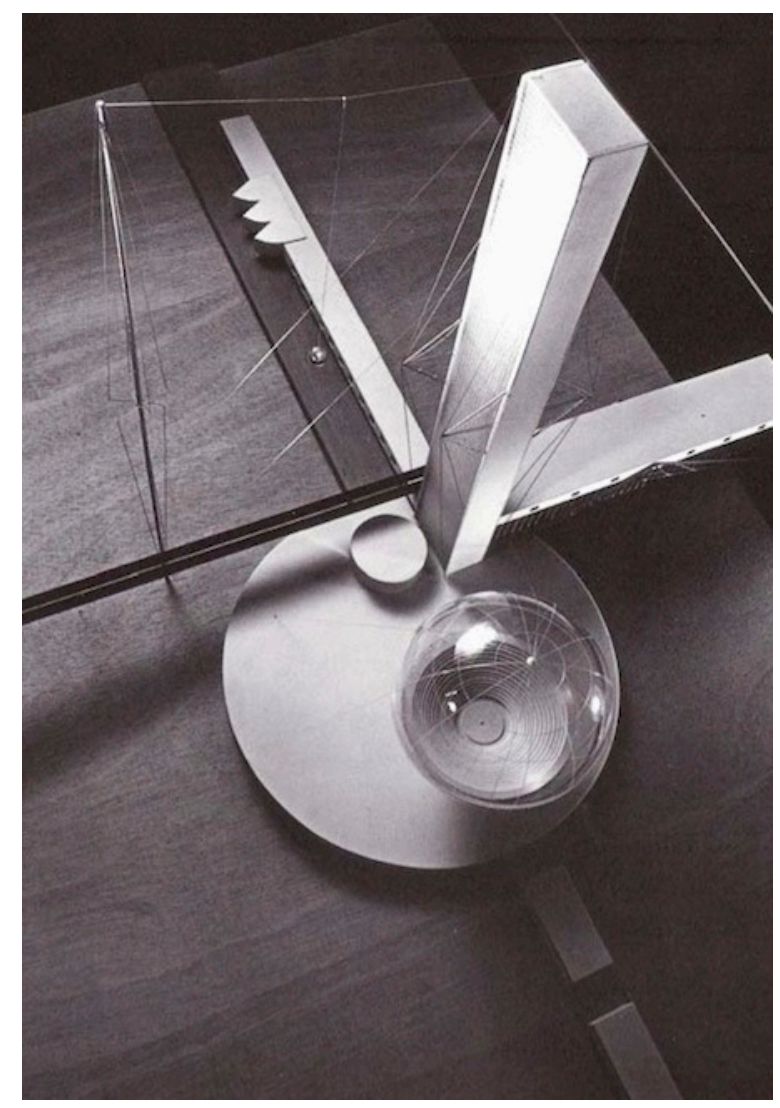

Figure 7: Model of the Lenin Institute, architect Ivan Leonidov, Modern reconstruction of the original model- the reconstruction was based on photographs of the original 1928 model. The reconstruction was included in the exhibition of the Russian Avant Garde in Saint Petersburg in 1999 (source utopia.ru)

The reason to chose this architectural studies by Leonidov is the influence the architect has had later on innovative architects of the twentieth century, such as OMA/Koolhaas (Koolhaas 1979) and F. O. Gehry, specifically in his later houses of the 80s such as Schnabel house residence (Blanciak 2014). Moreover, the specific oeuvre is ripe for grammatical analysis due to the constructivist style and method used: primary geometric forms and elements are used creatively for the composition. The Lenin Institute, consisting of Leonidov's diploma project in the Vkhutemas Architecture school is the first of a series of Avant-Garde projects that can be characterized as visions for the future (Collins 1979) or even utopian, characteristic of another, forward, progressive social order from Soviet Russia (Lowe 2010). Leonidov's preoccupation with geometric compositions will come to influence greats like Koolhaas and Gehry later in the twentieth century. The unique characteristic of Leonidov's compositions oscillate

between classism and modernism (Blanciak 2014), an oscillation that maps against the analytical and typological spectrum of the twentieth century as presented in this paper. Despite the Avant-Garde credentials of the Lenin Institute architectural study, the building does carry some inspiration from the Russian past, but looks resolutely towards the future, with its architectural members, even if in a reductionist manner, getting assembled in a manner reminiscing of the architecture of Russian churches. Leonidov's compositions are compiled by using four compositional principles, a feat that is present in the Lenin Institute as well: The use of pure forms, orthogonality, asymmetry, and the lack of nodes in an Afocal manner create the building blocks for Leonidov's compositions (Blanciak 2014). This leads Leonidov in an effort to create prototypes of scattered composition. 
Compositionally the building is a platform outside Moscow, on the hills that then were called 'Lenin' named after the revolutionary leader. Each of the volumes is a distinct form connected with the function that it houses, cancelling nonetheless any attempt to connect with known types of the era. The tower houses the library's bookshelves, with anticipation of future electronic collection and distributed system of books, while the amphitheatre takes the form of a glass sphere, sup- ported on a basis of concrete. The reading rooms are independent rooms and also distinct from the line of rooms that house the laboratories. The whole construction is shaped in a free asymmetrical composition in plan. The futuristic ambitions of the project are reflected in the numbers that drive its brief: the library is designed to take in 1.5 million volumes, the reading rooms can house 1000 readers simultaneously while the amphitheatre can hold 4000 persons simultaneously, with the additional complexity of having moving panels transform it to a planetarium or a science theatre. The project incorporates utopia for its era construction techniques, not yet widely available or validated by experience and use in Russia: ten- sioned cables and vast surfaces made out of glass dominate the composition, hence making potential realization costly and perhaps inefficient. The compositional relationship of the institute with Russian churches are evident in the plan and the related compositional arrangement. The compositional analysis though becomes easy once one recognizes that the Institute is also compiled with the use of several axes, initially placed in a colinear approach and then transformed with an off-centre placement.

Influenced by Suprematism, Leonidov does not represent at all the composition of the context. The landscape exists only in minimal terms and the architect is not interested at all in a dialectic with the surroundings. The main characteristic of the landscape from which the composition is articulated from is the railway line, which forms in one of the axes of the composition. This specific axis is the intense black line in the North-South Axis in most of Leonidov's drawings for the Lenin Institute, since according to Anders, Leonidov organizes everything according to axes. Stemming from this organization one of the shape gram- mars presented here follows an axial organization, including a centre of rotation. Of course, a grammar needs also the group Vt of graphic elements that constitute to the vocabulary of the grammar [figure Lenin institute vocabulary] (Figure 8).

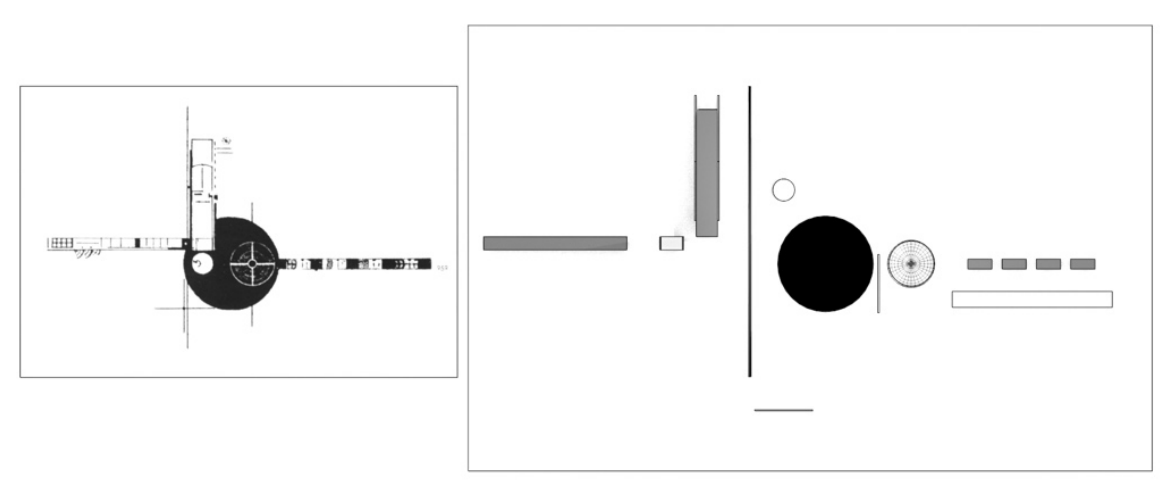

Figure 8: (right)Analysis of Group Vt of elements which are used by the dynamic shape grammar for producing variants of the design of the Lenin Institute plan (left)

The analysis in simple elements for the group Vt of the grammar follows the functional composition and structure of the building. Every shape constitutes a unique, autonomous, self-contained function, easily represented algebraically, making choosing a group $\mathrm{Vt}$ for the dynamic grammar easy. However, in this particular case, we will not only be examining one gram- mar but will explore how an analytical reading of the composition of the grammar for the Lenin Institute can lead through the application of animate dynamic grammars to the creation of more than one variants. Of course, shape generation in the dynamic grammar takes place in three dimensions while the initial creation of the grammar takes place in two dimensions, i.e. shape manipulation only happens in a two-dimensional plane (Figure 9). 


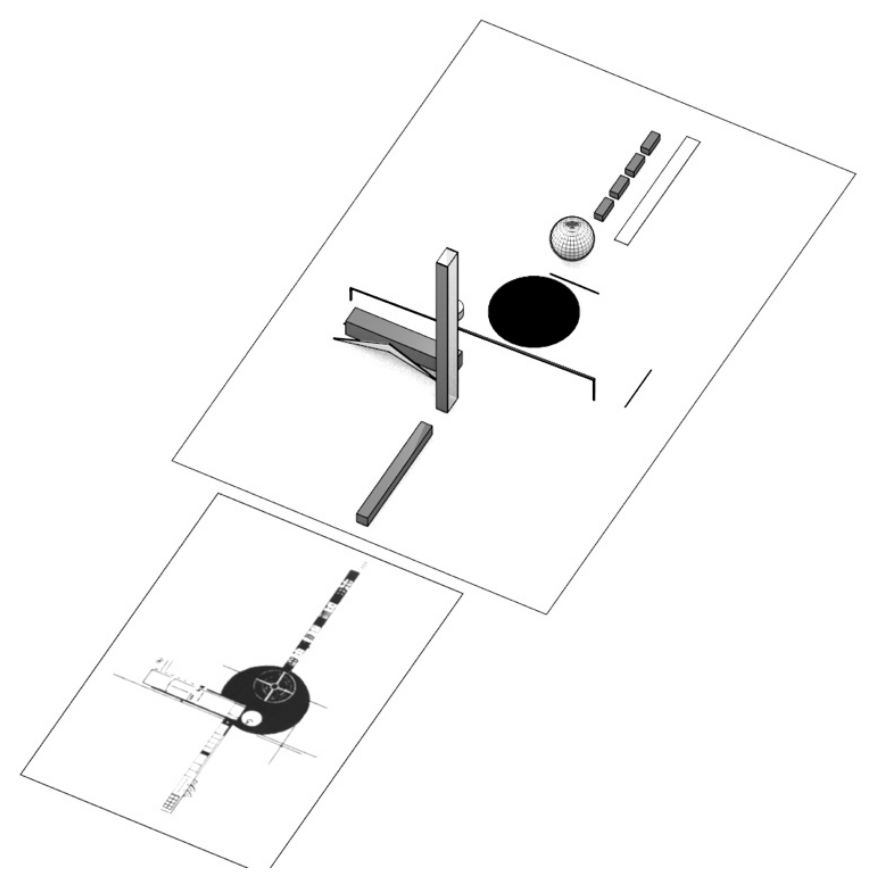

Figure 9: The initial group Vt of elements, in three dimensions, compared to the plan as designed by Leonidov.

In the three dimensional representation, the tensioned cables and the stabilizing cable mesh of the library are not represented, since they are secondary and follow always the bookshelves of the library. Shapes here are treated algebraically initially, which means that there is no transformation of the shape or change to the topology of the shape in a local geometrical manner. The only transformations that take place are location or rotation transformations. Also, scaling was avoided as a transformation, as it would completely and radically change the compositional balance of Leonidov.

The use of clean shapes, elementary pure geometric forms is an innovative vehicle for the architect of the era, elements of which we will find in the international movement \& modernist expression of the early twentieth century. Here the entertainment of the composition by Leonidov, takes place crucially by using a-symmetry. The initial compositional act is the axes, with the plan developing off-center, finding a dense com- position of its elemental geometric shapes, a method which is recognized by many researchers of Leonidov (Blanciak 2014) (Figure 10). 

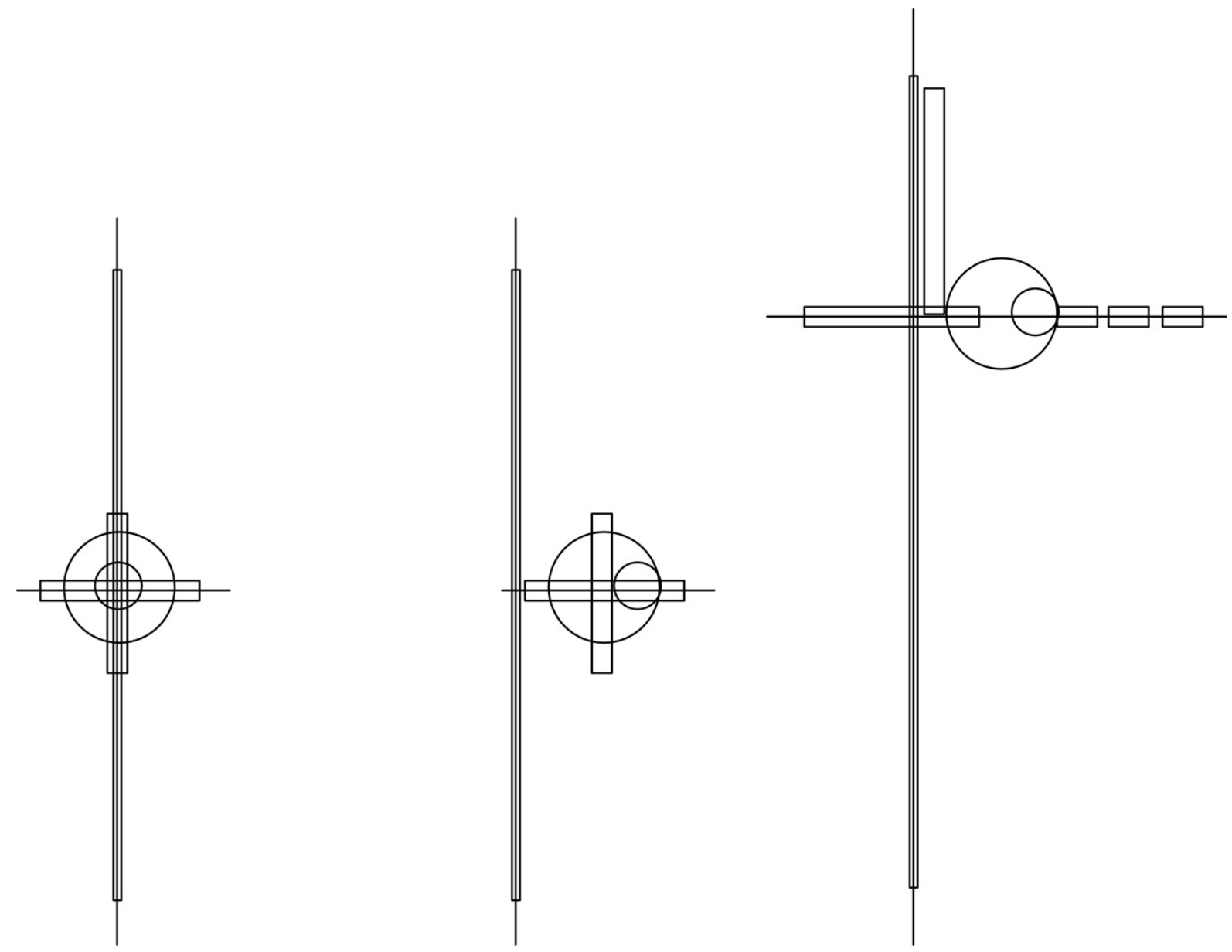

Figure 10: analysis of initial axial composition and off-centre development of the composition; source- Blanciak 2006 Leonidovisms, redrawn by the author.

\section{The first (dynamic) grammar}

The first dynamic grammar is constructed in a simple manner by rotating the elongated elements of group Vt around the centre of the circular platform, while on off-centre rotation the amphitheatre and the circular space for book distribution. The animation of this particular grammar, produces variants and at the same time, signifies the simplicity of the original compositional structure of Leonidov. In this first animation, there are no controlling mechanisms applied, just a key-frame animation expressing transformation rules. Every object gets transposed and moves freely, with the axial forces and the offcentre symmetry that Leonidov attempts as compositional principles of the transformation. The articulation of the synthesis from the axis of the railway line (the think black line in the original images of Leonidov) remains simple. In the original drawings, the railway line remains the framework of reference for the whole composition, as such the axis appears as an object that rotates- inside the dynamic grammar though what is important is the interrelationship of objects between them in an esoteric manner, rather than the relationship with the surrounding context. Due to that esoteric relationship, for the reading of the rules, the railway line remains parallel with the laboratory volume (Figures 11 and 12). 


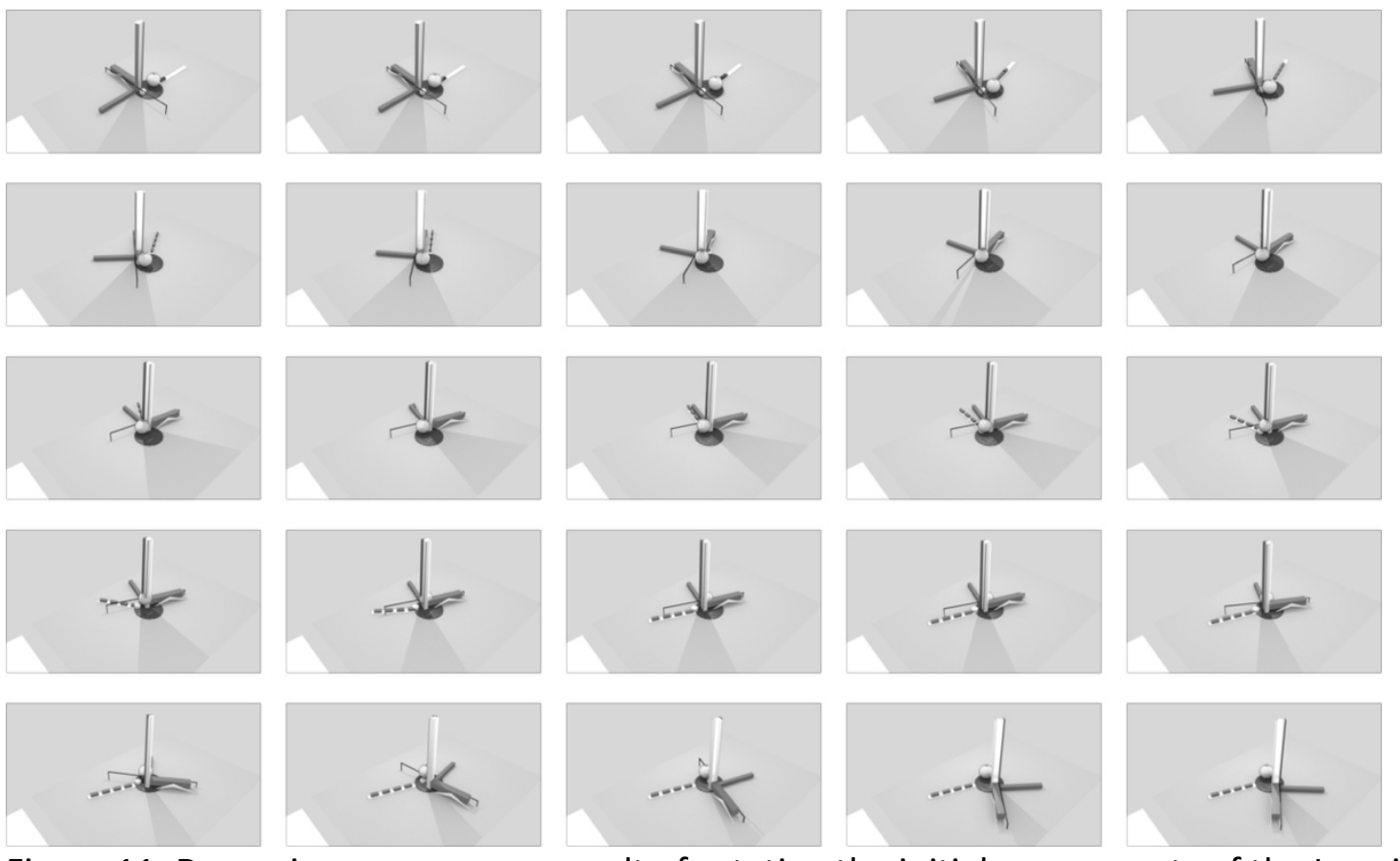

Figure 11: Dynamic grammar as a result of rotating the initial components of the Leonidov composition.

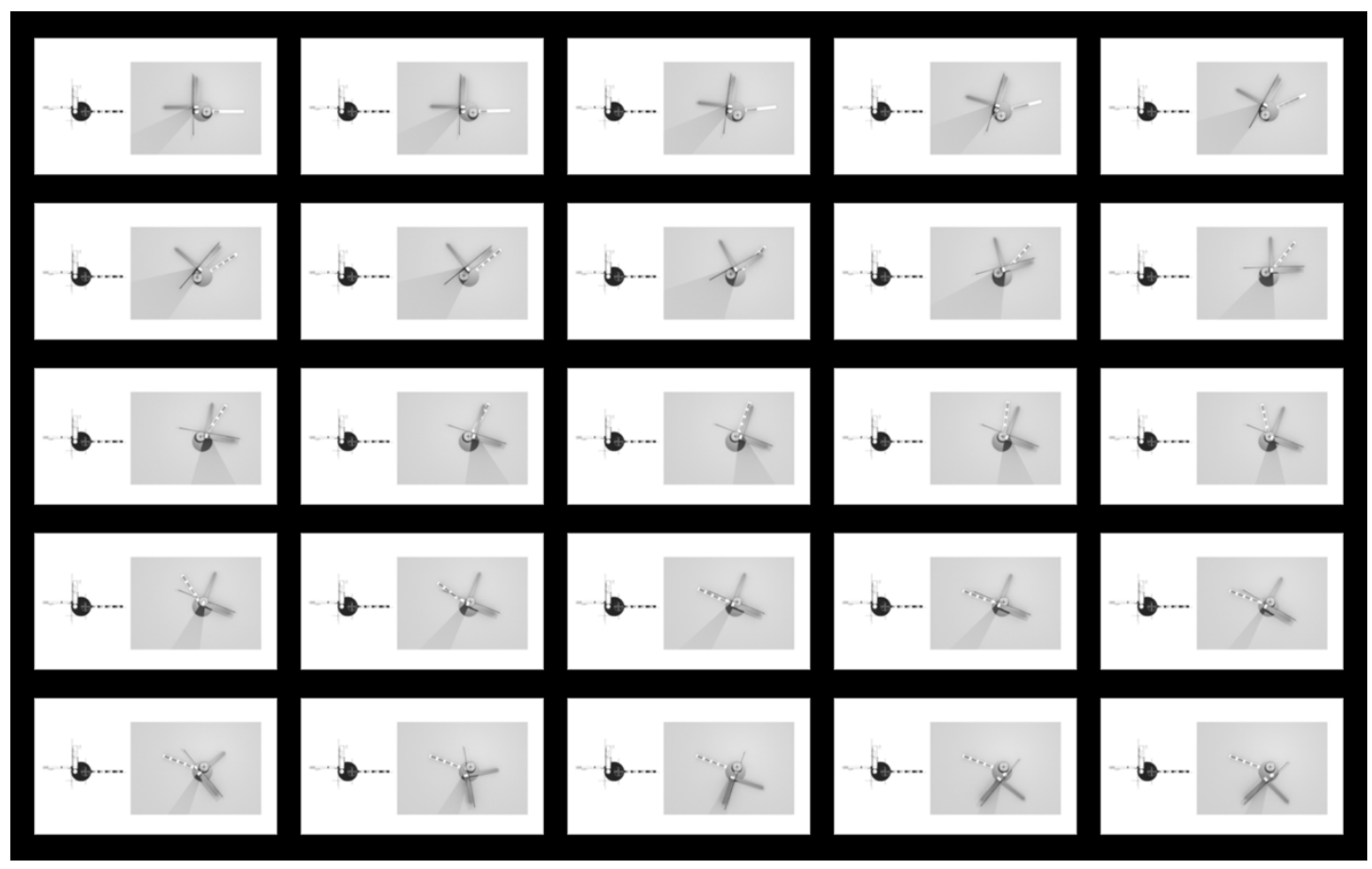

Figure 12: Dynamic grammar as a result of rotating the initial components of the Leonidov composition: comparison of variants with the initial grammar.

\section{The Second (dynamic) grammar}

The second grammar develops beyond simple rotation and maintaining the off-centre a-symmetry. Here the railway line remains in position according to the frame of the image. The grammar is used as a tool for generating the elementary geometrical shapes of Leonidov. The reading rooms, do not exist at the 
beginning of the generating animation, but spring up due to an array mechanism which is activated at frame 50 (Figures 13 and 14).

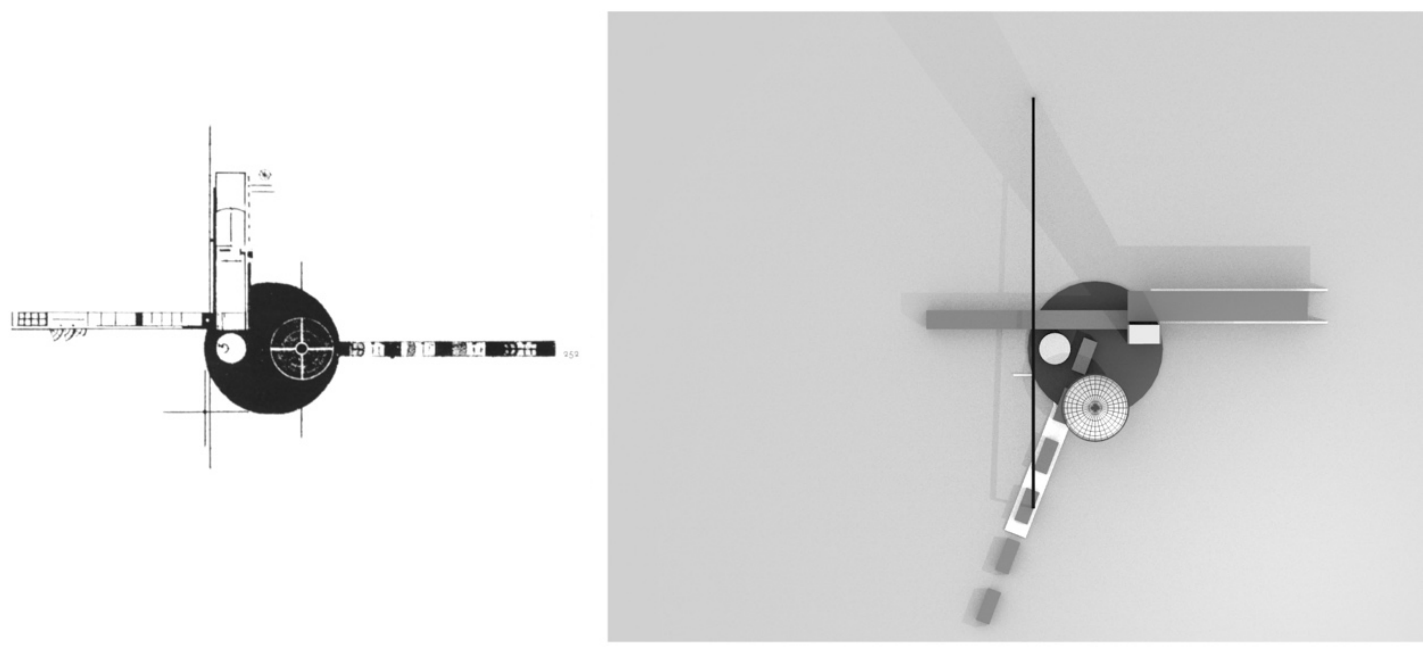

Figure 13: middle keyframe of the second grammar.
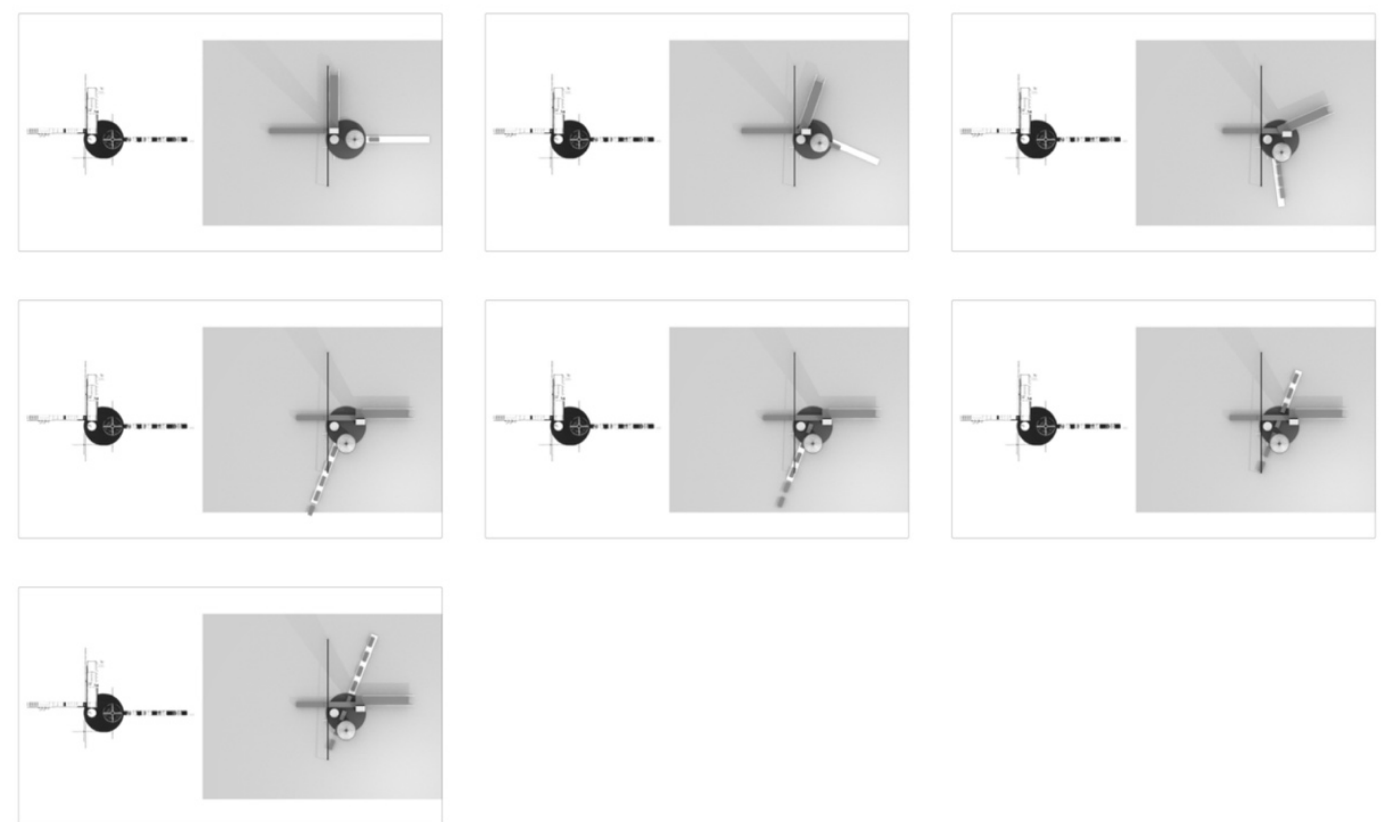

Figure 14: Frames of the second grammar every 10 frames. 


\section{The third (dynamic) grammar}

In the third attempt to analyse Leonidov's Lenin institute the grammar attempts to encapsulate the significance of the axes in Leonidov's composition, but also the asymmetry and off-centre production of the composition. The third dynamic grammar of Leonidov's lenin institute consists of three rules: the first rule generates the axial parallelepipeds, the second rule creates three equal copies of these, while the third rule rotates these copies so that the deflected composition of Leonidov gets created: A vertical axis and the two horizontal ones (Figure 15).
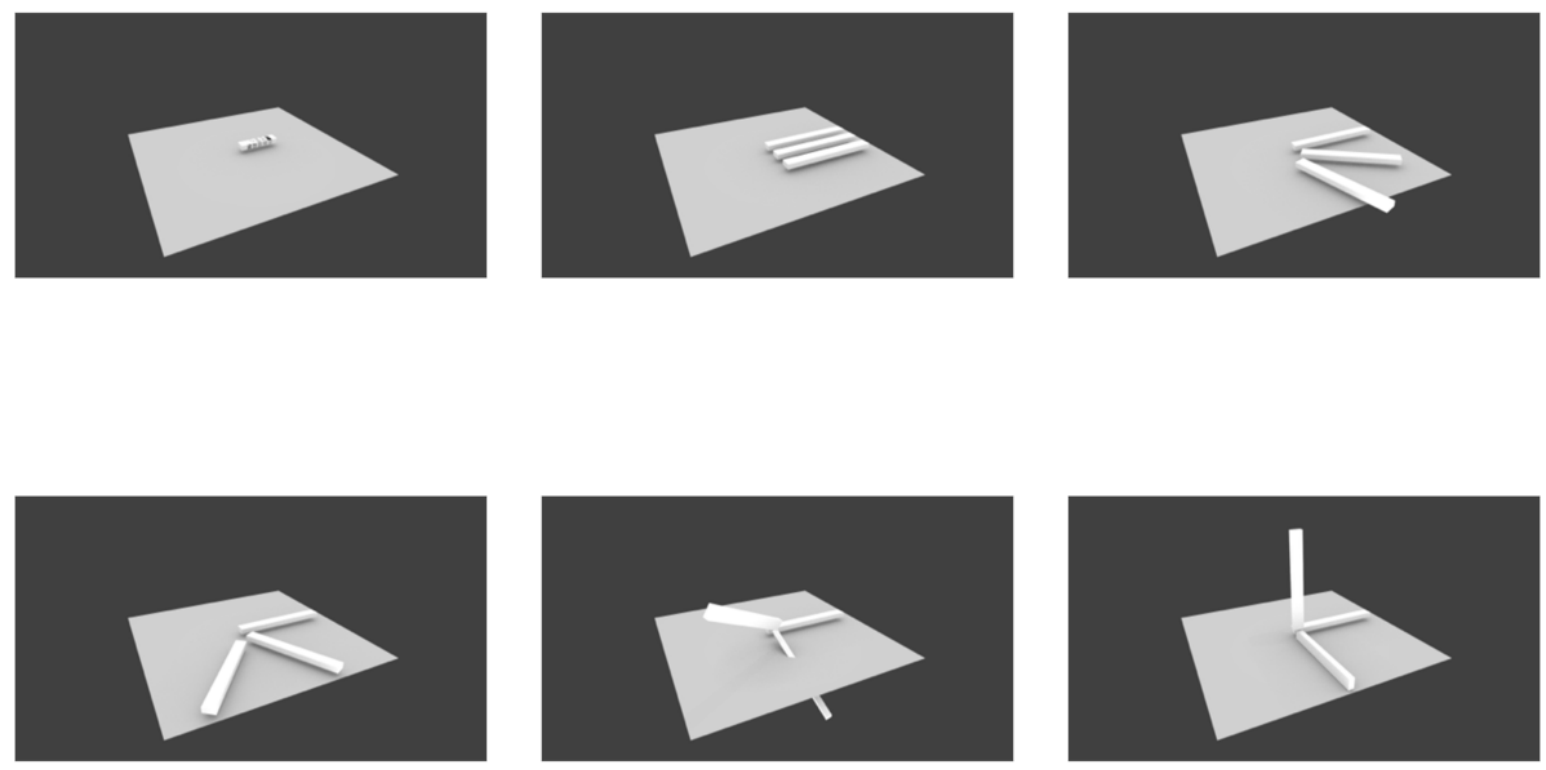

Figure 15: Key frames of the third dynamic grammar.

\section{The fourth (dynamic) grammar}

A fourth grammar is possible through the use of animation tools with a simple transformation and rotation rules along with changing the off-centre rotations within which these take place (Figure 16). 

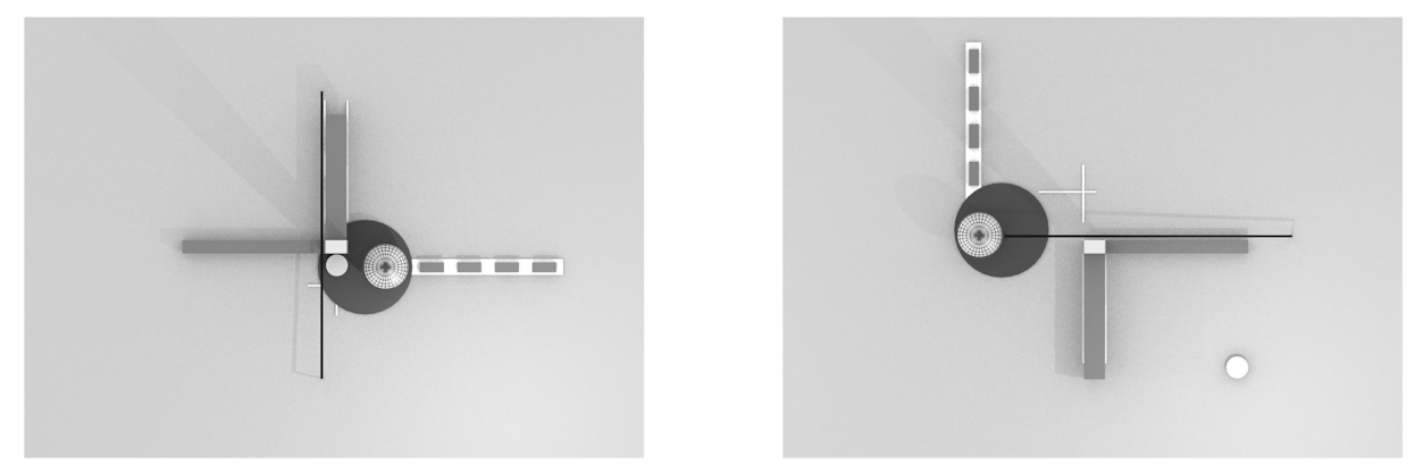

Figure 16: simple transposition of the elementary geometric shapes of Leonidov.

\section{Discussion}

The four Leonidov grammars demonstrate type innovation computationally, beyond the syntactical and typological framing of architecture. The greatest difficulty in using computation tools in architectural design lies with the difficulty in having an absolute meaning and signifier of architectural design within the binary understanding of Architecture in a typological manner and in a syntactical manner (Kotsiopoulos 1994). This difficulty, of course, also allows for experimentation, perhaps also in processes that initially appear playful but remain important new tools in con- trolling and producing designs. Within this binary condition of Architecture, Shape Grammars present a double answer: the designergrammarist can use a typological process in creating and using a shape gramma, which takes place in an algebraic level (Stiny 2006). This is due to the algebraic nature of defining shape grammars with groups at their beginning. The architect is called upon to create the group of rules that define the gram- mar but also the elementary geometric shapes that constitute the grammar, and the use of these two groups to design. Some grammars, develop in an algebraic manner, very close to pattern languages by Alexander, where the shapes contained within the group Vt, are already architectonic patterns/types, without any possibility to break them down further to more elementary levels. Within this supposition, belong all of the architectonic solutions architects invent by re-applying known solutions of the past. These types of solutions do not only restrain them- selves to plans but also are applied in elevations and in sections,

where the architect re-uses building elements in a compositional manner.

At the juxtaposition of this, we can of course also find the indivisibility of architectural shapes but also the infinite possibilities for embedding and emergence (Knight 2003a, 2003b; Stiny 2006) Instead, tracing the effort of shape grammars as a 'scientific' paradigm of design, one can find within the computational side of architectural design, the spectrum of both a typological and a syntactical approach to design.

Here two important events take place: the designer starts to design and at the same time creates atypically the rules he has to follow to apply the grammar that she needs. Instead, the elementary geometrical shapes in group Vt that are used are not declared a-priori, but are created in a bottom-up process, 
embedded in a top-down process recognized form the designer as the design process. Within this state, the designer does not recognize every time elementary geometrical shapes but she constructs them, and changes them according to her will (Stiny 2006). In a design process executed by hand, the designer is free to create and chose shapes and give them meaning in a complete ontological manner: a rectangle can be a Kitchen counter. This is a feat that is not yet possible through a computer, even though shape recognition and meaningful understanding can come from selected sets in A. I research (Wortmann and Stuffs 2018). Certainly, this freedom is crucial for the designer to explore what is possible within the design constraints.

Within the design process the designer remains free to continue through a process of shape emergence, with a grammatical process of design. This emergence can take place only if the designer, either a human or a machine, can recognize in drawings and provide meaning to new elementary shapes: see the rectangle and declare it a kitchen counter, or a bedroom, or assign to it any other meaning, but also every other possible subdivision and embedding, according to the strategy of design that she would need to develop. Computers can not yet do this step after recognition, and this is the step where the architectural design process takes place.

This, antithetically, positions shape grammars, when these are constructed during the design process, as an a-posteriori tool, not an a-priori tool, in the analytical spectrum of architectural design, where the elementary shapes are not recognizable from the beginning, but what matters are the emergence of shapes and boundaries (Knight 2003a, 2003b). With the parity of Dynamic Grammars and Shape Grammars, we can posi- tion animation as a computational understanding of architectural design, as a third pole between syntactical and typological understanding of design as shown already in Figure 5.

\section{The Syntactical-analytical Hypothesis.}

The basic correlation of dynamic grammars with the analytical and the syntactical hypothesis is the resolution that animation tools create a structuralism approach to architectural design, in line with the one that Hillier and Hanson (Hillier 2015) develop, when they are investigating means and tools such as depth of a plan and integration of a plan. This co-relation takes place even before the architect creates architectural variants solutions by using animation. Within the animation software, the architect creates the structure of an architectural solution, using rigging tools. This does not mean that the animation rigging structure reflects the meaning that the final architecture will encompass. Essentially the rigging, the analytical representation of the struc- ture of the idea, is a mechanism to structure production of variants, not the production of meaning.

One could argue that it does not matter if the architect under- stands this relationship when she is using the tool: defining meaning will come later and is going to be external. It will be within the production of architecture space that meaning will inscribe itself in space. Such a reading of the Rigging pro- cess and of the space syntax approach would be far away from

what Chomsky defines as generative systems. This deep struc- ture then is the same with the significance semiotic meaning it has, embedded within its product then. Even though according to Kotsiopoulos, Hillier and Hanson are very close to the devel- opment of a model of «autonomous syntax with an emphasis in the geometric and typological characteristics of the space» Stiny in his latest explorations on where do shapes come from (Stiny 2006) puts forward the idea that the shapes (and conse- quently their grammars-) are constructed by the architect with a process of seeing and doing. Within this framework, the vec- tor from the deep structure of an idea to its produced output is constructed by the architect: animation is the tool that is used for constructing the composition, independently from the method used to define meaning in theoretical terms. One thus can again be either analytical or typological in their search for meaning in architectural composition. Computation, in the form of dynamic grammars, then is really equal and equivalent to both the typological and analytical understanding of architecture. The question that arises then, is whether there is really a spectrum of analytical to typological understanding. How could we find ways to validate this working hypothesis? 
Within the confines of this paper we can only describe the next part as a hypothetical mental experiment, perhaps for other researchers more versed into operational research to take for- ward. One working method that we could use to return to the meaning and understanding of space through its composition tools would be to investigate the manner in which various archi- tects would use animation tools and analyse which actions are chosen when and in relation to which animation tool. Such a study would create the data to validate the hypothesis whether meaning is born at the compositional level, by interrogating the architects on their thinking during creation of their synthesis.

For the experiment, architects will be selected so that they participate in a series of design experiments, that will be observed operationally by the researchers. A design brief will be given to them, with specific parameters and needs in terms of the spaces, functions and constraints, and performance crite- ria. A simple training in animation tools is provided to them, so that they are capable to handle the requirements of the brief, using specifically animation tools. Then the experiment takes place, a recording of the way in which they use the tools is taking place while the architects along with a series of interviews of the architects before and after they are finished with the composition using animation tools. The interviews focus on whether the architects see the social dimension of their compo- sition and whether they inscribe meaning in their design at the moment they are using the compositional tools of the animation software.

The attention here does not lie with the value of the tools themselves in a mechanistic production but at the understand-ing or creating-inscribing meaning in using the tools. Within these conditions, it would be interesting to revisit in practice the notion that spatial configurations take place at the moment of their creation and we do not to think of the syntax of the space at the same moment and time we use language. The space accord- ing to Hillier encompasses the meaning, specifically the social meaning of space. This stems from the spatial configuration of each architecture. As such, the experiment should allow the architects to express their ideas on meaning and understanding

of architecture, producing variants of architectural design by using animation tools but also at a coalition level to group which action with which animation tool has specific meanings for these architects: Would we see two different architects using the same animation tool with the same understanding and meaning of the spatial configuration, or would these be always different?

Possibly such a result would validate the relationship between form and the meaning of space. Beyond the config- uration of shape grammars in such a mental experiment, the animation tools remain useful to architects as an expression of a compositional structure. Under these conditions, animation is more of an analytical tool when the architect is coalescing object relationships together and becomes productive as soon as an animation is produced, when movement and transformation happens.

\section{The Typological Hypothesis}

At the other end of the spectrum of the syntactical hypothesis lies the typological hypothesis. Within the framework of read-ing architecture by A. Colquhoun, between the relational and the symbolic, the perception is that the types are either images that have a style from which the architect selects which one to apply as if it was a colour palette, or either they have a generative character so that they only remain patterns that are embedded into architectural form. Again the shape grammar paradigm by Stiny can cater to both of these options by conveying both the symbolic and the generative.

Formally, due to the parity between shape grammars and ani- mation tools, animation can work either typologically by using algebras, or syntactically by constructing shapes as we have dis- cussed already. The difficult part of the typological hypothesis lies more at the process of using an algebraic process of design, at the moment when most architects are trained to only use soft- ware that operates in a visual manner. Of course, the process of constructing shapes in animation in relation to using a pen- cil and paper demands a great familiarity with the computer, as the reaction of the eye-hand coordination is immediate with trained architects, without having to use an algorithmic process in putting the rules together. 


\section{Conclusion: Constructing connection between Deep and Surface Structures: The computational hypothesis}

Animation tools can run the gradient between analytical and typological process depending on how the architect uses in each case the tools. The interest of course lies in the question of whether animation can be used also as a connecting tissue of deep structures and structures at the surface [Broadbent]. Can we observe the analytical action of breaking apart form in elementary basic geometrical shapes and its resynthesis in compositional structures, by using computation? At the same time can we see the production of variants as production of sur- face structures, i.e. the production of surface structures, variants being produced from one particular deep structure?

It is possible to understand Shape grammars and animation as an analytical approach to manipulate and construct com- positional structures. In that manner, dynamic grammars are able to generate architectonic constructs of ideas but they can

not embed within them the manner in which the drawing, the design will be evaluated. In this, meaning still gets pro- duced by the reader-architect. We can debate how this takes place in the mental experiment we described, but it always takes place externally to the grammar as the development of the case study showed. For that, the external reference points must have a relationship with an economic, social, environmen- tal or psychological understanding of architecture. Even though that weakness does exist dynamic grammars computationally retain the compositional structure at the heart of architectural design.

\section{Disclosure statement \\ No potential conflict of interest was reported by the Author}

ORCID http://orcid.org/0000-0002-2731-0493

\section{References}

Alexander, C. 1964. Notes on the Synthesis of Form. Cambridge, MA: Harvard University Press.

Alexander, C., S. Ishikawa, and M. Sliverstein. 1977. A Pattern Language, Towns, Buildings, Construction. Oxford: Oxford University Press. ISBN 0-19- 5019-19-9.

Blanciak, Francois. 2014. "Leonidovisms: Similarities and Differences Between Revolutionary Soviet Architecture and Contemporary Western Design Strategies." Journal of Civil Engineering and Architecture Research 1 (2): 79- 86.

Broadbent, G. 1980. Signs, Symbols and Architecture. Chichester: John Wiley \& Sons.

Collins, G. R. 1979. "Visionary Drawings of Architecture and Planning: 20th Century through the 1960s.” Art Journal 38 (4): 244-256.

Colquhoun, A. 1985. Essays in Architectural Criticism: Modern Architecture and Historical Change. Massachusetts: Opposition books.

Dounas, T. 2008. Dynamic Algebras and Grammars, Architecture in Computro, 26th eCAADe Conference Proceedings / ISBN 978-09541183-7-2. 
Dounas, T. 2013. 'Some Notes on the Incompleteness Theorem and Shape Grammars'. Zhang J., Sun C. (Eds) Global Design and Local Materialization. CAAD Futures 2013. Communications in Computer and Information Science, Vol 369. Springer, 369.

Dounas, T., and A. M. Kotsiopoulos. 2006. “Generation of Alternative Designs in Architectural Problems Using Shape Grammars Defined with Animation Tools - A Computer Implementation of Shape Grammars using Modelling and Animation Software, Communicating Space(s)." 24th eCAADe Conference Proceedings, Volos, Greece, September 6-9, pp. 302-307.

Dounas, T., and A. M. Kotsiopoulos. 2007. “Generative Systems Based on Animation Tools: Structure and Form of Core Ideas in Architectural Design, CAADRIA 2007.” Proceedings of the 12th International Conference on Computer Aided Architectural Design Research in Asia, Nanjing, China, April 19-21, pp. 433-440.

Duarte, J. P. 2005. "Towards the Mass Customization of Housing: The Grammar of Siza's Houses at Malagueira." Environment and Planning B: Planning and Design 32: 347-380.

Economou, A. 2001. "Four Algebraic Structures in Design". In Proceedings of the Twenty First Annual Conference of the Association for Computer-Aided Design in Architecture, 192-201. ACADIA.

Frayling, C. 1993. "Research in Art and Design.” Royal College of Art Research Papers 1 (1): 1-5.

Groat, L., and D. Wang. 2003. Architectural Research Methods. 2nd ed. London: Wiley.

Hiller, B. 2015. Space is the Machine. CreateSpace Independent Publishing Platform. http://spaceisthemachine.com.

Hiller, B., and A. Leaman. 1974. How is Design possible, J.A.R 3/1/1974 Hillier, B., and J. Hanson. 1989. The Social Logic of Space. Reprint edition. Cambridge: Cambridge University Press.

Knight, T. 2003a. “Computing with Ambiguity.” Environment and Planning B: Planning and Design 30: 165-180. Knight, T. 2003b. “Computing with Emergence." Environment and Planning B: Planning and Design 30: $125-155$. Koolhaas, R. 1979. “The Future's Past.” The Wilson Quarterly 3 (1): 135-140.

Kotsiopoulos, Anastasios, M. 1994. Critique of Architectural Theory. Thessaloniki: University Studio Press. original in Greek:

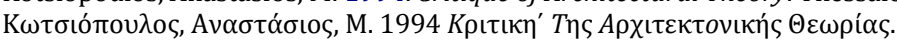

Lowe, D. 2010. Channelling the Past: Tradition and Politics in Ivan Leonidov's "Utopian Constructivism" 65-66 Twelfth Conference of the International Association for the Study of Traditional Environments, December 15-18, 2010, American University of Beirut (AUB), Beirut, Lebanon.

Rendell, J. 2004. “Architectural Design and Disciplinarity." Architectural Research Quarterly 8 (2): 141-147. doi:10.1017/S135913550400017X.

Stiny, G. 2006. Shape, Talking About Seeing and Doing. Cambridge, MA: MIT Press

Wortmann, T., and R. Stuffs. 2018. "Algorithmic Complexity of Shape Grammar Implementation." In Artificial Intelligence for Engineering Design, Analysis and Manufacturing. Vol. 32., edited by Sara Elloy, Pieter Pauwells, and Athanasios Economou, $138-146$. Cambridge: Cambridge University Press. doi:10.1017/S0890060417000440.

Web:

1. Utopia.ru 